\title{
Infant Temperament Affects Toddler Language Development
}

\section{Linnea Davison ${ }^{1}$ \\ Haven Warwick ${ }^{2}$ \\ Kaitlyn Campbell ${ }^{3}$ (I) \\ Maria A. Gartstein ${ }^{4}$ (D)}

${ }_{1,2,3,4}$ Department of Psychology Washington State University Pullman, WA, USA.

Email:linnea.davison@wsu.eduTel:(360)589-2115

2Email:haven.warwick@wsu.eduTel.(509)592-6497

Email:kaitlyn.campbell@wsu.edu Tel:(208)739-7376

"Email: gartstma@rwsu.eduTel:(509)533-4651

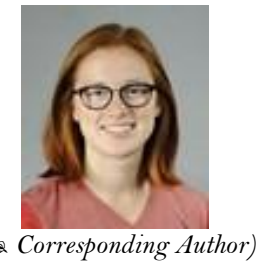

( Corresponding Author)

Abstract

An extensive literature links language problems with behavioral difficulties and academic underachievement. Although less extensive, emerging literature suggests that temperament, Positive Affectivity (PA) in particular, contributes to language development. Thus, the present study was focused on PA related temperament dimensions in infancy as predictors of early expressive language. Mothers $(\mathrm{N}=148)$ were recruited and administered a temperament questionnaire when their infants were 8 and 12 months of age. PA scales: Activity (ACT), Smiling $\&$ Laughter (SL), High-Intensity Pleasure (HP), Perceptual Sensitivity (PS), Approach (APP), and Vocal Reactivity (VR) were considered. A follow-up evaluation addressing language development - vocabulary and phrase length, was conducted at 24 months of age $(n=85)$. Length of phrases positively correlated with PS and APP at 8 and 12 months, and VR at 8 months. Infants' vocabulary score was positively correlated with PS at 8 months and 12 months, and APP at 12 months. Further hierarchical multiple regression analyses indicated that ACT and APP at 8months uniquely predicted phrase length, whereas PS and APP of 8-month infants contributed to later vocabulary scores. PS at 12-months predicted vocabulary scores, after accounting for covariates and other PA attributes.

Keywords: Infant, Language development, Temperament, Language development, Positive affect.

Citation | Linnea Davison; Haven Warwick; Kaitlyn Campbell; Maria A. Gartstein (2019). Infant Temperament Affects Toddler Language Development. Journal of Education and e-Learning Research, 6(3): 122-128.

History:

Received: 19 March 2019

Revised: 24 April 2019

Accepted: 27 May 2019

Published: 8 August 2019

Licensed: This work is licensed under a Creative Commons

Attribution 3.0 License (oc)

Publisher: Asian Online Journal Publishing Group
Acknowledgement: All authors contributed to the conception and design of the study.

Funding: This study is received NIMH Small Research Grant (Ro3 MH067010).

Competing Interests: The authors declare that they have no conflict of interests.

Transparency: The authors confirm that the manuscript is an honest, accurate, and transparent account of the study was reported; that no vital features of the study have been omitted; and that any discrepancies from the study as planned have been explained.

Ethical: This study follows all ethical practices during writing.

\section{Contents}

1. Introduction

3. Results

References... 


\section{Contribution of this paper to the literature}

This study contributes to the existing literature by focusing on positive affectivity related temperament dimensions in infancy as predictors of early expressive language.

\section{Introduction}

Relations between language problems and behavioral difficulties, as well as academic underachievement are emphasized in existing research. Language development has been related to the development of self-regulation and behavior problems (Vallotton and Ayoub, 2011; Petersen et al., 2015; Norbury et al., 2016; Chow et al., 2018). Aro et al. (2012) found that combined deficits in self-regulation and early language play an important role in predicting social functioning (i.e., were related to lower adaptability three years later). Rescorla et al. (2007) further found that toddlers with language delays appeared to show elevated social withdrawal relative to typically developing toddlers. Not surprisingly, children with expressive language delays are more likely to have symptoms of pervasive developmental problems (Tervo, 2007). For example, toddlers with delayed expressive language appear did not exhibit developmentally appropriate social skills at 18 months of age (Tervo, 2007). Roben et al. (2013) found that children's growth in terms of language skills contributed to a decline in anger expression and enhanced strategies they could initiate to regulate their frustration. That is, children with higher language skills used calm support seeking and distraction as regulatory strategies - they approached parents using their more advanced expressive language capabilities, explaining their needs, or distracted themselves more effectively and for longer periods of time.

Language delays can further contribute to the development of symptoms/behavior problems, such as inattention-hyperactivity (Petersen et al., 2013; Visser et al., 2017). Thurm et al. (2018) found that toddlers identified as having a language delay were more likely to exhibit externalizing problems, internalizing problems, and dysregulation as compared to toddlers with typical language development. Toddlers in the language delay group also demonstrated lower competence scores, including compliance, attention, mastery motivation, imitation/play, empathy, and prosocial peer relations. Although toddlers in the language delay group and the typically developing group differed significantly on all outcome measures, competence was the only domain in which the majority of the language delay group was reported to be in the clinical concern range (Thurm et al., 2018). Similarly, 4-year olds with language impairment were vulnerable to difficulties in temperament/behavioral problem domains, compounding existing risk from poorer language development. These children were significantly different from their typically developing counterparts in persistence, "easy-difficult" aspects of temperament, conduct problems, and total behavioral difficulties, just prior to school entry (Prior et al., 2011).

Language delays during preschool years were predictive of behavioral deviance (externalizing behavior problems), hyperactivity, and reading deficits during grade school (Hinshaw, 1992). Tomblin et al. (2000) reported that children with language impairment often demonstrate associated problems of learning and behavior, such as reading disabilities and behavior disorders. In another study, language competence was the strongest contributor to academic achievement, with the youngest children, more likely to exhibit language difficulties, at the highest risk for behavior problems and poor academic attainment in their first year of formal schooling (Norbury et al., 2016). The youngest children in a grade were twice as likely to have language difficulties compared to their older peers which were significantly associated with behavior problems (Norbury et al., 2016). Importantly, language performance at 10 months was significantly correlated with cognitive and educational dysfunction 10 years later, predicting academic achievement in the 4th grade (Hohm et al., 2007). Given these noted links between language issues and developing social skills, cognitive, and educational dysfunction, it is critical to further understand the factors that contribute to language deficits in early childhood.

Although less extensive, an emerging literature links temperament to language development. Laake and Bridgett (2014) found that infant Positive Affectivity (PA) at 10 months predicted expressive language at 14 months. Three sub-dimensions of PA predicted expressive language and two sub-dimensions were trend-level predictors of expressive language: Activity Level, High Intensity Pleasure, and Approach, predicted expressive language, whereas Perceptual Sensitivity, and Vocal Reactivity, were trend level predictors (Laake and Bridgett, 2014). When comparing pre-term and full-term infants' biological, cognitive, and temperament predictors of language development, temperament appeared to have the strongest effect (Pérez-Pereira et al., 2016). Specifically, Approach, High Intensity Pleasure, and Soothability, as well as Low Intensity Pleasure and Sadness (in a negative relation), had the strongest effects on word production for both full-term and preterm infants (Pérez-Pereira et al., 2016). Links between temperament and language development are not restricted to infancy, and have been demonstrated in toddlerhood as well. When assessed at age 2, the temperament dimension of Positive AffectExtraversion accounted for variance in language skills at age 3 and 7 (Slomkowski et al., 1992). In addition, Salley and Dixon (2007) showed that temperament scores correlated with joint attention and language measures, but only temperament was predictive of language development (Salley and Dixon, 2007). Children classified as presenting with a "typical" temperamental profile, assessed by parents and teachers, exhibited the most advanced linguistic abilities (Garello et al., 2012). The typical profile was to as such as it was demonstrated by the majority of youngsters, and was associated with good social orientation, low inhibition to novelty, medium-high positive emotionality and attention (Garello et al., 2012).

Given the consistent role of positive emotionality-related traits in existing research, the present study was focused on Positive Affect/Surgency temperament dimensions, identifying fine-grained facets in infancy most critical to later language development. The aim was thus to identify early temperament precursors of emerging language capabilities in the toddler period. We focused on the fine-grained Positive Affect/Surgency dimensions because these have been demonstrated as important predictors of language development (e.g., Pérez-Pereira et al. (2016)) and because existing research suggests narrowly defined temperament traits are important to consider as scales associated with the same over-arching factor differ with respect to predictive relations, contributions to temperament types, and growth trajectories (Oldehinkel et al., 2004; Lengua, 2006; Gartstein et al., 2017; Gartstein and Hancock, 2019). Based on the available literature, it was hypothesized that fine-grained components of Positive Affect/Surgency, especially Approach and High Intensity Pleasure, would independently predict expressive 
language development operationalized as the average phrase length and a vocabulary score (i.e., number of words produced spontaneously).

\section{Methods}

\subsection{Participants}

A community sample of 148 English speaking mothers with 4-month-old infants from adjacent communities in Eastern Washington and Northeastern Idaho were recruited through birth announcements released by hospitals and published in a local newspaper, as well as the primary prevention program First Steps. First Steps provided information about this research, along with developmental information aimed at preventing child maltreatment, to all parents of newborn infants in the local hospitals, regardless of risk factors. Project staff contacted potential participants identified through First Steps (i.e., those indicating an interest in this study) by telephone. None of the potential participants recruited through the help of the First Steps program decline participation, whereas seven families contacted on the published birth announcements decided not to take part in this research. Only families with healthy infants were eligible to participate and completed temperament evaluations at 8 and 12 months. The follow-up assessment addressing emerging behavior problems was conducted at 24 months of age, when 85 of the original families (46 of male and 39 of female children) responded to the surveys. Non-responders either could not be reached $(n=40)$, wherein either the telephone number had been disconnected or the family did not respond to recruitment calls and letter, or were reached but declined participation $(n=23)$, most frequently citing lack of time as a reason.

\subsection{Measures}

The Infant Behavior Questionnaire-Revised (IBQ-R; Gartstein and Rothbart (2003)) is a parent-report measure of temperament for infants between 3- and 12-months of age. This 191-item instrument yields 14 scales shown to form three over-arching factors: Positive Affectivity/Surgency (Activity Level, Smiling/Laughter, Approach, High Intensity Pleasure, Perceptual Sensitivity, and Vocal Reactivity), Negative Emotionality (Fear, Distress to Limitations, Sadness, and negatively loading Falling Reactivity), and Regulatory Capacity/Orienting (Duration of Orienting, Soothability, Cuddliness/Affiliation, and Low Intensity Pleasure). Reliability of the IBQ-R has been supported for mothers and fathers, as well as samples from different cultures, with Cronbach's $\alpha$ values ranging from .77 to .96 (Gartstein and Rothbart, 2003; Gartstein et al., 2003; Parade and Leerkes, 2008) and there is evidence supporting predictive and construct validity of this instrument (Gartstein and Bateman, 2008; Gartstein and Marmion, 2008; Gartstein et al., 2010). Internal Consistency of the 14 IBQ-R subscales in the present sample was generally good, with the Cronbach's $\alpha$ values ranging from .65 to .96 (mean $\alpha=.82$ ). Only fine-grained dimensions associated with the Positive Affectivity/Surgency factor were considered in this study.

The Child Behavior Checklist (CBCL; Achenbach and Rescorla (2000)) for ages 18 months to five years, containing 100 items, was administered during follow-up around 24 months of age. Specifically, the Language Development Survey was used. The Language Development Survey lists a series of words (e.g., foods, body parts, actions, animals) and asks parents to indicate which words the child says spontaneously (beyond imitation or understanding the given word ). The parents are also asked to provide five of the longest phrases the child is able to produce, with the average phrase length computed on the basis of this sample. Total scores were converted to reflect the child's percentile relative to same age peers using norms provided by the authors and reported for descriptive purposes. CBCL vocabulary indicators correlate in the moderate range with scores on standardized vocabulary tests $(r s=.66-.87$; (Klee et al., 1998; Rescorla and Alley, 2001)). Reliability and validity of this measure have been established, with adequate criterion-related validity (Achenbach and Rescorla, 2000) as well as interrater $(r s=.40-.75)$ and test-retest reliability $(r s=.80-.90)$.

\subsection{Procedure}

Mothers reported demographic factors when their infants were 4 months of age. Parent-reported child temperament indicators considered in this study were obtained at 8 and 12 months of age. Mothers were asked to complete the IBQ-R within two weeks of their child turning each of the target ages. These children were subsequently followed-up into the second year of life, with mothers responding to the CBCL at about 24 months of age, providing markers of emerging language competence. Questionnaires included in this investigation were mailed to the parents and completed at home, at their convenience.

\subsection{Analytic Strategy}

Descriptive statistics were computed first. Next, we considered Pearson Product Moment Correlation coefficients among the predictors and outcome variables considered in this study. Finally, hierarchical multiple regressions were performed with Positive Affect/Surgency fine-grained scales: Activity, Smiling and Laughter, High Intensity Pleasure, Perceptual Sensitivity, Approach, and Vocal Reactivity, considering vocabulary score and average phrase length as dependent variables and controlling for child sex and age at follow-up.

\section{Results}

Demographic information and descriptive statistics are presented in Table 1. Pearson's product-moment correlations were computed to examine associations between the independent and dependent variables examined in this study. A number of significant and trend-level simple correlations were observed for the Positive Affectivity/Surgency fine-grained domains. Specifically, length of phrases positively correlated with Perceptual Sensitivity and Approach at 8 and 12 months, and Vocal Reactivity at 8 months Tables $2 \mathrm{a}$ and 2b. Infants' vocabulary score was positively correlated with Perceptual Sensitivity at 8 months and 12 months, and Approach at 12 months. Therefore, higher levels of Perceptual Sensitivity and Approach at 8 and 12 months predicted longer lengths of phrases, with Vocal Reactivity at 8 months associated with longer phrase length. Greater Perceptual 
Sensitivity at 8 and 12 months further predicted higher infants' vocabulary score; and higher levels of Approach at 12 months predicting higher vocabulary score.

Table-1. Descriptive statistics: Primary caregiver and child demographics; independent and dependent variables.

\begin{tabular}{|c|c|c|c|c|c|}
\hline & Variable & Mean/Median & Range & Standard Deviation & Percentage \\
\hline Maternal age (years) & & 28.67 & $20-42$ & 5.27 & \\
\hline \multicolumn{6}{|l|}{ Child sex } \\
\hline & Males & & & & $50.8 \%$ \\
\hline & Females & & & & $49.2 \%$ \\
\hline $\begin{array}{c}\text { Child's age at follow- } \\
\text { up (months) }\end{array}$ & & 22.01 & $18-33$ & & 3.14 \\
\hline \multicolumn{6}{|c|}{ Ethnicity } \\
\hline & Caucasian & & & & $91.9 \%$ \\
\hline & African American & & & & $3.7 \%$ \\
\hline & Asian & & & & $2.9 \%$ \\
\hline & Hispanic/Latino & & & & $1.5 \%$ \\
\hline \multicolumn{6}{|l|}{ Living arrangement } \\
\hline & Married & & & & $93.1 \%$ \\
\hline & Divorced/separated & & & & $1.6 \%$ \\
\hline & Single & & & & $3.8 \%$ \\
\hline & Remarried & & & & $1.5 \%$ \\
\hline \multirow{6}{*}{$\begin{array}{l}\text { Highest educational } \\
\text { attainment (years) }\end{array}$} & & 15.87 & $10-20$ & 2.29 & \\
\hline & $\begin{array}{l}\text { Less Than High } \\
\text { School }\end{array}$ & & & & $2.8 \%$ \\
\hline & $\begin{array}{l}\text { High School } \\
\text { Diploma }\end{array}$ & & & & $6.4 \%$ \\
\hline & Some College & & & & $26.2 \%$ \\
\hline & Bachelor's Degree & & & & $39.7 \%$ \\
\hline & Graduate Degree & & & & $24.8 \%$ \\
\hline \multicolumn{6}{|l|}{ Family income } \\
\hline & $\$ 0-\$ 7,000$ & & & & $5.2 \%$ \\
\hline & $\$ 7,001-\$ 10,000$ & & & & $3.0 \%$ \\
\hline & $\$ 10,001-\$ 13,000$ & & & & $5.2 \%$ \\
\hline & $\$ 13,001-\$ 16,000$ & & & & $4.5 \%$ \\
\hline & $\$ 16,001-\$ 20,000$ & & & & $9.0 \%$ \\
\hline & $\$ 20,001-\$ 30,000$ & & & & $10.4 \%$ \\
\hline & $\$ 30,001-\$ 50,000$ & & & & $29.9 \%$ \\
\hline & $\$ 50,001-\$ 75,000$ & & & & $17.2 \%$ \\
\hline & Over $-\$ 75,000$ & & & & $15.7 \%$ \\
\hline \multicolumn{6}{|c|}{ Positive Affectivity/Surgency Scales ( 8 months) } \\
\hline & Activity Level & 4.57 & $2.62-6.53$ & 0.80 & \\
\hline & Smiling/Laughter & 4.49 & $2.00-6.20$ & 0.97 & \\
\hline & Approach & 5.27 & $3.33-6.83$ & 0.91 & \\
\hline & $\begin{array}{l}\text { High Intensity } \\
\text { Pleasure }\end{array}$ & 5.86 & $4.18-7.00$ & 0.67 & \\
\hline & $\begin{array}{l}\text { Perceptual } \\
\text { Sensitivity }\end{array}$ & 3.85 & $1.00-6.00$ & 1.15 & \\
\hline & Vocal Reactivity & 4.68 & $2.18-6.25$ & 0.91 & \\
\hline \multicolumn{6}{|c|}{ Positive Affectivity/Surgency Scales (12 months) } \\
\hline & Activity Level & 4.76 & $2.80-6.33$ & 0.76 & \\
\hline & Smiling/Laughter & 4.56 & $2.10-6.60$ & 0.91 & \\
\hline & Approach & 5.60 & $3.42-7.00$ & 0.67 & \\
\hline & $\begin{array}{l}\text { High Intensity } \\
\text { Pleasure }\end{array}$ & 5.94 & $4.00-7.00$ & 0.61 & \\
\hline & $\begin{array}{l}\text { Perceptual } \\
\text { Sensitivity }\end{array}$ & 4.07 & $1.22-6.67$ & 1.12 & \\
\hline & Vocal Reactivity & 5.06 & $2.92-6.75$ & 0.89 & \\
\hline \multicolumn{6}{|c|}{ Vocabulary score and phrase length percentiles } \\
\hline & Vocabulary score & 55 (median) & $15-90$ & & \\
\hline & Length of phrase & 30 (median) & $1-90$ & & \\
\hline
\end{tabular}

Table-2a. Simple correlations: Infant Temperament at 8 months with Average Length of Phrases and Vocabulary Score.

\begin{tabular}{|c|c|c|c|c|c|c|}
\hline & Activity & $\begin{array}{l}\text { Smiling \& } \\
\text { Laughter }\end{array}$ & $\begin{array}{c}\text { High Intensity } \\
\text { Pleasure }\end{array}$ & $\begin{array}{l}\text { Perceptual } \\
\text { Sensitivity }\end{array}$ & Approach & $\begin{array}{c}\text { Vocal } \\
\text { Reactivity }\end{array}$ \\
\hline Average Length of Phrases & .17 & $.19^{\S}$ & $.19^{\S}$ & $.26^{*}$ & $.28^{*}$ & $.24^{*}$ \\
\hline Vocabulary Score & .15 & .14 & .11 & $.30^{* *}$ & $.21 \S$ & $.21^{\S}$ \\
\hline
\end{tabular}

Table-2b. Simple correlations: Infant Temperament at 12 months with Average Length of Phrases and Vocabulary Score.

\begin{tabular}{|c|c|c|c|c|c|c|}
\hline & Activity & $\begin{array}{l}\text { Smiling \& } \\
\text { Laughter }\end{array}$ & $\begin{array}{l}\text { High Intensity } \\
\text { Pleasure }\end{array}$ & $\begin{array}{l}\text { Perceptual } \\
\text { Sensitivity }\end{array}$ & Approach & $\begin{array}{c}\text { Vocal } \\
\text { Reactivity }\end{array}$ \\
\hline Average Length of Phrases & .15 & .16 & .16 & $.27^{*}$ & $.25^{*}$ & .18 \\
\hline Vocabulary Score & .15 & .16 & .17 & $.33^{* *}$ & $.25^{*}$ & $.17 \S$ \\
\hline
\end{tabular}

${ }^{* *} \mathrm{p}<0.01 ; * \mathrm{p}<0.05 ;{ }^{\S} \mathrm{p}<0.10$ 
Further hierarchical multiple regression analyses indicated that Activity and Approach at 8-months uniquely predicted phrase length, whereas Perceptual Sensitivity and Approach of 8 -month infants contributed to later vocabulary scores Tables $3 \mathrm{a}$ and $3 \mathrm{~b}$. Perceptual Sensitivity at 12-months predicted vocabulary scores, after accounting for covariates (child sex and age) and other Positive Affect/Surgency attributes Table 3c. None of the Positive Affect/Surgency related attributes measured at 12 months of age emerged as significant predictors of average phrase length.

Table-3a. Hierarchical Multiple Regression: Infant Temperament at 8 months predicting Average Phrase Length.

\begin{tabular}{c|c|c|c|c|c|c}
\hline Variable & & $\mathbf{R}$ & $\mathbf{R}^{2}$ & $\mathbf{R}^{2} \Delta$ & $\mathbf{F} \Delta$ & Beta \\
\hline Model 1 & & .50 & .25 & .25 & $12.96^{* *}$ & \\
\hline & Infant Sex & & & & & -.05 \\
\hline & Infant Age & & & & & $.50^{* *}$ \\
\hline Model 2 & & .61 & .37 & .12 & $2.19{ }^{\S}$ & $-.65^{*}$ \\
\hline & & Activity & & & & -.12 \\
\hline & & Smiling \& Laughter & & & & -.23 \\
\hline & & High Intensity Pleasure & & & & .12 \\
\hline & & Perceptual Sensitivity & & & & $.95^{* *}$ \\
\hline & & Approach & & & & .14 \\
\hline
\end{tabular}

\begin{tabular}{c|c|c|c|c|c|c}
\multicolumn{6}{c}{ Table-3b. Hierarchical Multiple Regression: Infant Temperament at 8 months predicting Vocabulary Score. } \\
\hline Variable & & $\mathbf{R}$ & $\mathbf{R}^{\mathbf{2}}$ & $\mathbf{R}^{\mathbf{}} \Delta$ & $\mathbf{F} \Delta$ & Beta \\
\hline Model 1 & & .63 & .40 & .40 & $27.38^{* *}$ & \\
\hline & Infant Sex & & & & & -.14 \\
\hline & Infant Age & & & & & $62^{* *}$ \\
\hline Model 2 & & .70 & .49 & .09 & $2.144^{\S}$ & $-.40^{\S}$ \\
\hline & & Activity & & & & $-.05^{\S}$ \\
\hline & & Smiling \& Laughter & & & & -.53 \\
\hline & & High Intensity Pleasure & & & & $.37^{*}$ \\
\hline & & Perceptual Sensitivity & & & & $.59^{*}$ \\
\hline & & Approach & & & & .21 \\
\hline
\end{tabular}

Table-3c. Hierarchical Multiple Regression: Infant Temperament at 12 months predicting Vocabulary Score.

\begin{tabular}{|c|c|c|c|c|c|c|}
\hline Variable & & $\overline{\mathbf{R}}$ & $\mathbf{R}^{2}$ & $\mathbf{R}^{2} \Delta$ & $\mathbf{F} \Delta$ & Beta \\
\hline \multirow[t]{3}{*}{ Model } & & .63 & .40 & .40 & $27.38^{* * *}$ & \\
\hline & Infant Sex & & & & & -.14 \\
\hline & Infant Age & & & & & -.62 \\
\hline \multirow[t]{7}{*}{ Model 2} & & .71 & .50 & .10 & $2.56^{*}$ & \\
\hline & & Activity & & & & -.13 \\
\hline & & Smiling \& Laughter & & & & .13 \\
\hline & & High Intensity Pleasure & & & & $-.53 \S$ \\
\hline & & Perceptual Sensitivity & & & & $.33^{*}$ \\
\hline & & Approach & & & & $.44 \$$ \\
\hline & & Vocal Reactivity & & & & -.07 \\
\hline
\end{tabular}

** $\mathrm{p}<0.01 ; * \mathrm{p}<0.05 ; \$ \mathrm{p}<0.10$.

\section{Discussion}

The primary aim of this study was to determine how fine-grained infant temperament attributes were related to early expressive language development. This research expands on the existing literature by the virtue of this fine-grained focus in connecting positive emotionality and markers of language development. A nuanced pattern of results was obtained, with Approach and Perceptual Sensitivity emerging as the fine-grained temperament traits most consistently linked with length of phrases and vocabulary scores.

Fine-grained dimensions associated with Positive Affect/Surgency likely uniquely contribute to language development as children who receive high scores on these attributes seek out situations that allow them to advance in expressive language (Laake and Bridgett, 2014). Specifically, children high in temperament traits related to extroversion may be more likely to engage in social interactions with adults and older children compared to infants with low levels of Positive Affect/Surgency attributes (Slomkowski et al., 1992). Furthermore, infants with higher Approach tendencies may use emerging language skills to elicit more social interactions, helping to create additional opportunities to develop language through socially reinforced practice (Laake and Bridgett, 2014).

Infant Perceptual Sensitivity may have also emerged as an important predictor of language development because high Perceptual Sensitivity scores indicate that infants are able to attend to subtle aspects of their environment and stimulation (Gartstein and Rothbart, 2003) an attribute that likely facilitates language acquisition. Additionally, Perceptual Sensitivity clusters with Positive Affectivity scales during infancy because it may be indicative of reactive reward orientation under the influence of a Surgency system. Later in childhood it is typically a component of the effortful control factor, which reflects flexible self-regulation, often defined as "an ability to suppress a prepotent response in favor of a novel adaptive response" (Putnam et al., 2006).

Conversely, children lower in their ability to experience positive emotions, or with a negative reactive temperament, may be less able to attend to and process relevant language cues (Leve et al., 2013). Language skills may facilitate self-regulation by serving as a cognitive tool to comprehend and plan one's own behavior (Vallotton 
and Ayoub, 2011). Language allows for the comprehension of regulatory-related directives from others and facilitates the mental organization of internal regulatory processes (Vallotton and Ayoub, 2011). Prior et al. (2011) explains that the relationship between negative affectivity and language development "potentiates risk for less than optimal outcomes in the school years where poorer self-regulation capacities and behavioral adjustment added to language impairment compromise learning progress". Early intervention to address language concerns is vital in improving a child's school readiness, as children with language impairments may exhibit challenging behaviors creating a higher risk for reading and other academic difficulties (Chow et al., 2018). Although we did not measure receptive language, expressive language typically lags behind comprehension in development (Bates et al., 1995). Thus, children higher in expressive language competence can be expected to possess superior receptive language skills as well.

Although these results require replication, if supported by future studies, low levels of Positive Affect/Surgency (Approach and Perceptual Sensitivity in particular) could be identified in clinical screenings and used to target at-risk children. Because our work addresses parental report of early language markers, and not language disorders per se, the identified children would only be considered at-risk for language development deemed less advanced than peers of comparable ages. Nonetheless, parents could be informed about such risk in a probabilistic manner and provided with materials that may help to foster word/phrase production in early childhood, as well as implementing effective communication interventions that have positive effects on child language outcomes (Chow et al., 2018). Moreover, parent-implemented functional communication interventions could also teach children to use communication without resorting to problem behaviors (Chow et al., 2018). This strategy could lead to improving child language development outcomes with minimal cost, possibly implemented by primary care providers.

The limitations of the present study include the sample size and research design. Although the sample size was sufficient for the current research, a larger sample would provide better representative and generalizable results to the studied population. The recruitment methods and nature of the research also led to a majority of the participants to be middle class with at least some college education. Additionally, the current study focused solely on the relationship between infant temperament and language development within a narrow time frame. It is important to consider various facets of language development over a long period of time to determine the full affect infant temperament has on language development.

Nonetheless, this work demonstrates the importance of identifying infant temperament precursors of early language markers, as early detection of language delays and providing appropriate intervention could help with the trajectory of a child's social and behavioral development, as well as academic success. Prospective research should further investigate the various facets of language development implementing performance tests along with parentreport and considering parent-child interaction factors along with infant temperament. A more extensive longitudinal evaluation would also be important to conduct, considering contributions of temperament growth trajectories and changes in language acquisition over time. Finally, future research should include more representative and larger samples to enhance power and generalizability.

\section{References}

Achenbach, T.M. and L.A. Rescorla, 2000. . Manual for the ASEBA preschool forms \& profiles: An integrated system of multi-informant assessment. Burlington, VT: AESBA.

Aro, T., K. Eklund, J.-E. Nurmi and A.-M. Poikkeus, 2012. Early language and behavioral regulation skills as predictors of social outcomes. Journal of Speech, Language, and Hearing Research, 55(2): 395-408.Available at: https://doi.org/10.1044/1092-4388(2011/100245 .

Bates, E., P. Dale and D. Thal, 1995. Individual differences and their implications for theories of language development. In the Handbook of Child Language, Fletcher, Paul, \& Mac Whinney, Brian [Eds], Oxford, England: Blackwell Publishers, 1995, pp: 96-151.

Chow, J.C., E. Ekholm and H. Coleman, 2018. Does oral language underpin the development of later behavior problems? A longitudinal meta-analysis. School Psychology Quarterly, 33(3): 337-349.Available at: https://doi.org/10.1037/spq0000255.

Garello, V., P. Viterbori and M.C. Usai, 2012. Temperamental profiles and language development: A replication and an extension. Infant Behavior and Development, 35(1): 71-82.Available at: https://doi.org/10.1016/j.infbeh.2011.09.003.

Gartstein, M.A. and A.E. Bateman, 2008. Early manifestations of childhood depression: Influences of infant temperament and parental depressive symptoms. Infant and Child Development: An International Journal of Research and Practice, 17(3): 223-248.Available at: https://doi.org/10.1002/icd.549.

Gartstein, M.A., D.J. Bridgett, M.K. Rothbart, C. Robertson, E. Iddins, K. Ramsay and S. Schlect, 2010. A latent growth ex amination of fear development in infancy: Contributions of maternal depression and the risk for toddler anxiety. Developmental Psychology, 46(3): 651-668.Available at: https://doi.org/10.1037/a0018898.

Gartstein, M.A. and G.R. Hancock, 2019. Temperamental growth in infancy: Demographic, maternal symptom, and stress contributions to overarching and fine-grained dimensions. Merrill-Palmer Quarterly, 65(2): 121-157.Available at: https://doi.org/10.13110/merrpalmquar 1982.65.2.0121.

Gartstein, M.A. and J. Marmion, 2008. Fear and positive affectivity in infancy: Convergence/discrepancy between parent-report and laboratory-based indicators. Infant Behavior and Development, 31(2): 227-238.Available at: https://doi.org/10.1016/j.infbeh.2007.10.012.

Gartstein, M.A., A. Prokasky, M.A. Bell, S. Calkins, D.J. Bridgett, J. Braungart-Rieker, E. Leerkes, C.L. Cheatham, R.D. Eiden and K.D. Mize, 2017. Latent profile and cluster analysis of infant temperament: Comparisons across person-centered approaches. Developmental Psychology, 53(10): 1811-1825.Available at: https://doi.org/10.1037/dev0000382.

Gartstein, M.A. and M.K. Rothbart, 2003. Studying infant temperament via the revised infant behavior questionnaire. Infant Behavior and Development, 26(1): 64-86.Available at: https://doi.org/10.1016/s0 163-6383(02)00169-8.

Gartstein, M.A., H.R. Slobodskaya and I.A. Kinsht, 2003. Cross-cultural differences in temperament in the first year of life: United States of America (US) and Russia. International Journal of Behavioral Development, 27(4): 316-328.Available at: https://doi.org/10.1080/01650250244000344.

Hinshaw, S.P., 1992. Externalizing behavior problems and academic underachievement in childhood and adolescence: Causal relationships and underlying mechanisms. Psychological Bulletin, 111(1): 127-155.Available at: https://doi.org/10.1037//0033-2909.111.1.127.

Hohm, E., C. Jennen-Steinmetz, M.H. Schmidt and M. Laucht, 2007. Language development at ten months. European Child \& Adolescent Psychiatry, 16(3): 149-156.Available at: https://doi.org/10.1007/s00787-006-0567-y.

Klee, T., D.K. Carson, W.J. Gavin, L. Hall, A. Kent and S. Reece, 1998. Concurrent and predictive validity of an early language screening program. Journal of Speech, Language, and Hearing Research, 41(3): 627-641.Available at: https://doi.org/10.1044/jslhr.4103.627.

Laake, L.M. and D.J. Bridgett, 2014. Happy babies, chatty toddlers: Infant positive affect facilitates early expressive, but not receptive language. Infant Behavior and Development, 37(1): 29-32.Available at: https://doi.org/10.1016/j.infbeh.2013.12.006. 
Lengua, L.J., 2006. Growth in temperament and parenting as predictors of adjustment during children's transition to adolescence. Developmental Psychology, 42(5): 819-832.Available at: https://doi.org/10.1037/0012-1649.42.5.819.

Leve, L.D., D.S. DeGarmo, D.J. Bridgett, J.M. Neiderhiser, D.S. Shaw, G.T. Harold, M.N. Natsuaki and D. Reiss, 2013. Using an adoption design to separate genetic, prenatal, and temperament influences on toddler executive function. Developmental Psychology, 49(6): 1045-1057.Available at: https://doi.org/10.1037/a0029390.

Norbury, C.F., D. Gooch, G. Baird, T. Charman, E. Simonoff and A. Pickles, 2016. Younger children experience lower levels of language competence and academic progress in the first year of school: Evidence from a population study. Journal of Child Psychology and Psychiatry, 57(1): 65-73.Available at: https://doi.org/10.1111/jcpp.12431.

Oldehinkel, A.J., C.A. Hartman, A.F. De Winter, R. Veenstra and J. Ormel, 2004. Temperament profiles associated with internalizing and externalizing problems in preadolescence. Development and Psychopathology, 16(2): 42 1-440.

Parade, S.H. and E.M. Leerkes, 2008. The reliability and validity of the infant behavior questionnaire-revised. Infant Behavior and Development, $31(4)$ : 637-646.Available at: https://doi.org/10.1016/j.infbeh.2008.07.009.

Pérez-Pereira, M., P. Fernández, M. Resches and M.L. Gómez-Taibo, 2016. Does temperament influence language development? Evidence from preterm and full-term children. Infant Behavior and Development, 42: 11-21.Available at: https://doi.org/10.1016/j.infbeh.2015.10.003.

Petersen, I.T., J.E. Bates, B.M. D'Onofrio, C.A. Coyne, J.E. Lansford, K.A. Dodge, G.S. Pettit and C.A. Van Hulle, 2013. Language ability predicts the development of behavior problems in children. Journal of Abnormal Psychology, 122(2): 542-557.Available at: https://doi.org/10.1037/a0031963.

Petersen, I.T., J.E. Bates and A.D. Staples, 2015. The role of language ability and self-regulation in the development of inattentivehyperactive behavior problems. Development and Psychopathology, 27(1): 221-237.Available at: https://doi.org/10.1017/s0954579414000698.

Prior, M., E. Bavin, E. Cini, P. Eadie and S. Reilly, 2011. Relationships between language impairment, temperament, behavioural adjustment and maternal factors in a community sample of preschool children. International Journal of Language \& Communication Disorders, 46(4): 489-494.Available at: https://doi.org/10.1111/j.1460-6984.2011.00003.x.

Putnam, S.P., M.A. Gartstein and M.K. Rothbart, 2006. Measurement of fine-grained aspects of toddler temperament: The early childhood behavior questionnaire. Infant Behavior and Development, 29(3): 386-401.Available at: https://doi.org/10.1016/j.infbeh.2006.01.004.

Rescorla, L. and A. Alley, 2001. Validation of the language development survey (LDS): A parent report tool for identifying language delay in toddlers. Journal of Speech, Language, and Hearing Research, 44(2): 434-445.Available at: https://doi.org/10.1044/10924388(2001/035).

Rescorla, L., G.S. Ross and S. McClure, 2007. Language delay and behavioral/emotional problems in toddlers: Findings from two developmental clinics. Journal Of Speech Language And Hearing Research, 50(4): 1063-1078.Available at: https://doi.org/10.1044/1092-4388(2007/074.

Roben, C.K., P.M. Cole and L.M. Armstrong, 2013. Longitudinal relations among language skills, anger expression, and regulatory strategies in early childhood. Child Development, 84(3): 891-905.Available at: https://doi.org/10.1111/cdev.12027.

Salley, B.J. and J.W.E. Dixon, 2007. Temperamental and joint attentional predictors of language development. Merrill-Palmer Quarterly (Wayne State University. Press), 53(1): 131-154.Available at: https://doi.org/10.1353/mpq.2007.0004.

Slomkowski, C.L., K. Nelson, J. Dunn and R. Plomin, 1992. Temperament and language: Relations from toddlerhood to middle childhood. Developmental Psychology, 28(6): 1090-1095.Available at: https://doi.org/10.1037//00 12-1649.28.6.1090.

Tervo, R.C., 2007. Language proficiency, development, and behavioral difficulties in toddlers. Clinical Pediatrics, 46(6): 530-539.Available at: https://doi.org/10.1177/0009922806299154.

Thurm, A., S.S. Manwaring, C. Cardozo Jimenez, L. Swineford, C. Farmer, R. Gallo and M. Maeda, 2018. Socioemotional and behavioral problems in toddlers with language delay. Infant Mental Health Journal, 39(5): 569-580.Available at: https://doi.org/10.1002/imhj.21735.

Tomblin, J.B., X. Zhang, P. Buckwalter and H. Catts, 2000. The association of reading disability, behavioral disorders, and language impairment among second-grade children. The Journal of Child Psychology and Psychiatry and Allied Disciplines, 41(4): 473482.Available at: https://doi.org/10.1017/s002196300000559x.

Vallotton, C. and C. Ayoub, 2011. Use your words: The role of language in the development of toddlers' self-regulation. Early Childhood Research Quarterly, 26(2): 169-181.Available at: https://doi.org/10.1016/j.ecresq.2010.09.002.

Visser, J.C., N.N. Rommelse, M. Lappenschaar, I.J. Servatius-Oosterling, C.U. Greven and J.K. Buitelaar, 2017. Variation in the early trajectories of autism symptoms is related to the development of language, cognition, and behavior problems. Journal of the American Academy of Child \& Adolescent Psychiatry, 56(8): 659-668.Available at: https://doi.org/10.1016/j.jaac.2017.05.022. 